\title{
Neurobehavioural disturbances, rehabilitation outcome, and lesion site in patients after rupture and repair of anterior communicating artery aneurysm
}

\author{
Stefanie Böttger, Mario Prosiegel, Hans-Jakob Steiger, Alexander Yassouridis
}

\begin{abstract}
Objective-To determine: (1) patterns of cognitive and psychiatric dysfunction; (2) those neurobehavioural parameters which mostly influence disability in activities of daily living (ADL) and handicap in occupational and psychosocial activities, and (3) underlying neuroanatomical pathology in patients after rupture and repair of anterior communicating artery (ACoA) aneurysm.

Methods-30 patients were extensively examined by means of a comprehensive battery of neuropsychological tests, by rating of psychopathological symptoms, and by use of the functional independence measure (FIM), Glasgow outcome scale (GOS), and MRI.
\end{abstract}

Results and conclusions-(1) Three main groups were characterised by primary impairment of memory, executive functions, or of attentional performance. Within these main groups, specific patterns were identified relating to extent of primary dysfunction and associated disorders. The variety of neuropsychological disturbances is in contradiction to the existence of an "ACoA syndrome" as an entity. (2) Rehabilitation outcome proved to be mostly associated with both memory and attentional performance. (3) In neuropathological terms, lesions of the medial septum and nucleus of the diagonal band of Broca (MS/ndbB) were closely associated with memory deficits and prefrontal lesions were associated with attentional, executive, and psychopathological dysfunctions. At the same time, bilateral lesions were associated with severe disturbances. The type and severity of the above mentioned deficits were independent of the side of lesion in unilateral cases, of rectus gyrus resection, and of the Hunt and Hess grading system.

(F Neurol Neurosurg Psychiatry 1998;65:93-102)

Keywords: anterior communicating artery (ACoA) aneurysm; neurobehavioural disturbances; rehabilitation outcome

After rupture and repair of anterior communicating artery (ACoA) aneurysms patients In the past were often reported as having severe cognitive deficits and psychopathological symptoms which remained permanent in many cases. In the meantime reports accumulated about only mild to moderate deficits and good recovery in many patients. This change was interpreted as a consequence of improved preoperative, intraoperative, and postoperative management in modern neurosurgery. ${ }^{1}$

Accordingly, studies carried out on patients with ACoA published hitherto can be divided into two categories. In earlier studies a chronic mental disorder was described showing the main symptoms of severe amnesia, personality changes, and confabulation. The deficits were compared with the Wernicke-Korsakoff syndrome and they were given the term "ACoA syndrome". ${ }^{2-6}$

Recent studies no longer characterised the "ACoA syndrome" exclusively as a global amnesic syndrome. They differ in three respects from the earlier studies: Firstly, a differentiation was made between a mild and severe degree of memory deficit and personality change. ${ }^{7}$ Secondly, studies aimed to achieve a qualitative in depth analysis of memory deficits. In this context one special subject of interest in patients with ACoA was the learning of contextual information. ${ }^{89}$ In particular, the linking together of target information with spatial location or time tag was found to be severely impaired in patients with memory disorders. Another special subject of interest in patients with AcoA was their sensitivity to proactive interference when learning two or more sets of information. ${ }^{10}$ Another focus of interest was the preservation of priming and skill learning. ${ }^{11}$ Thirdly, other cognitive impairments were also considered, especially frontal dysfunctions, mainly in the form of concept formation deficiency and perseverative responding. ${ }^{12-14}$

It is necessary to emphasise that an assessment of the total range of attentional processes has not been adequately performed to date. General screening of concentration disclosed either normal attentional performance or deficiency of complex attentional processes. ${ }^{13} 71415$ Furthermore, rehabilitation outcome of patients with ACoA has not been studied at all.

In the present study, therefore, we looked for connections between neuropsychological test results and the underlying neuroanatomical pathology on the one hand and outcome in terms of activities of daily living as well as of occupational and psychosocial activities on the other. In doing so, the levels of impairment, disability, and handicap, as defined by the 
Table 1 Characteristics of sample $(n=30)$

\begin{tabular}{|c|c|c|c|c|c|c|c|c|}
\hline \multirow[b]{2}{*}{ Case No } & \multirow[b]{2}{*}{$\operatorname{Sex}$} & \multirow[b]{2}{*}{ Age at onset } & \multirow[b]{2}{*}{$S A H$ grade } & \multicolumn{2}{|c|}{ Site of lesion } & \multirow[b]{2}{*}{$\begin{array}{l}\text { Resection of } \\
\text { rectus gyrus }\end{array}$} & \multicolumn{2}{|c|}{ Months after injury } \\
\hline & & & & $M S / n d b B$ & Prefrontal & & $\begin{array}{l}\text { Cognitive } \\
\text { testing }\end{array}$ & $\begin{array}{l}\text { Outcome } \\
\text { rating }\end{array}$ \\
\hline 1 & $\mathrm{~F}$ & 65 & IV & Bil & Bil & $\mathrm{Y}$ & 8 & 20 \\
\hline 2 & $\mathrm{~F}$ & 66 & V & $\mathrm{R}$ & Bil & $\mathrm{N}$ & 8 & 38 \\
\hline 3 & $\mathrm{~F}$ & 68 & III & $\mathrm{R}$ & $\mathrm{R}$ & $\mathrm{N}$ & 5 & 15 \\
\hline 4 & $\mathrm{~F}$ & 68 & III & $\mathrm{R}$ & - & $\mathrm{Y}$ & 4 & 5 \\
\hline 5 & $\mathrm{~F}$ & 37 & IV & $\mathrm{R}$ & $\mathrm{R}$ & $\mathrm{Y}$ & 3 & 5 \\
\hline 6 & $\mathrm{~F}$ & 62 & II & $\mathrm{R}$ & $\mathrm{R}$ & $\mathrm{N}$ & 7 & 19 \\
\hline 7 & $\mathrm{~F}$ & 49 & IV & $\mathrm{R}$ & - & $\mathrm{Y}$ & 10 & 24 \\
\hline 8 & $\mathrm{~F}$ & 48 & V & $\mathrm{L}$ & Bil & $\mathrm{N}$ & 5 & 19 \\
\hline 9 & $\mathrm{~F}$ & 52 & III & $\mathrm{L}$ & $\mathrm{R}$ & $\mathrm{Y}$ & 5 & 29 \\
\hline 10 & M & 72 & II & $\mathrm{L}$ & $\mathrm{L}$ & $\mathrm{Y}$ & 2 & 9 \\
\hline 11 & $\mathrm{~F}$ & 47 & IV & $\mathrm{L}$ & $\mathrm{L}$ & $\mathrm{N}$ & 4 & 7 \\
\hline 12 & $\mathrm{~F}$ & 60 & III & Bil & $\mathrm{L}$ & $\mathrm{N}$ & 9 & 10 \\
\hline 13 & $\mathrm{~F}$ & 56 & IV & $\mathrm{L}$ & - & $\mathrm{Y}$ & 3 & 5 \\
\hline 14 & M & 59 & II & $\mathrm{R}$ & $\mathrm{R}$ & $\mathrm{N}$ & 5 & 16 \\
\hline 15 & M & 52 & III & - & $\mathrm{L}$ & $\mathrm{N}$ & 5 & 30 \\
\hline 16 & M & 38 & II & $\mathrm{L}$ & $\mathrm{R}$ & $\mathrm{N}$ & 6 & 18 \\
\hline 17 & $\mathrm{~F}$ & 61 & IV & $\mathrm{L}$ & $\mathrm{L}$ & $\mathrm{Y}$ & 3 & 25 \\
\hline 18 & M & 55 & I & $\mathrm{L}$ & $\mathrm{L}$ & $\mathrm{Y}$ & 5 & 7 \\
\hline 19 & M & 37 & II & $\mathrm{L}$ & Bil & $\mathrm{Y}$ & 4 & 6 \\
\hline 20 & $\mathrm{~F}$ & 60 & II & - & - & $\mathrm{Y}$ & 8 & 28 \\
\hline 21 & M & 66 & II & - & - & $\mathrm{Y}$ & 5 & 10 \\
\hline 22 & $\mathrm{~F}$ & 46 & II & $\mathrm{R}$ & $\mathrm{R}$ & $\mathrm{Y}$ & 2 & 15 \\
\hline 23 & $\mathrm{~F}$ & 39 & IV & $\mathrm{L}$ & - & $\mathrm{N}$ & 4 & 7 \\
\hline 24 & M & 39 & IV & $\mathrm{L}$ & - & $\mathrm{N}$ & 2 & 5 \\
\hline 25 & M & 59 & II & Bil & - & $\mathrm{N}$ & 13 & 13 \\
\hline 26 & $\mathrm{~F}$ & 68 & IV & $\mathrm{R}$ & - & $\mathrm{Y}$ & 2 & 6 \\
\hline 27 & $M$ & 54 & I & $\mathrm{R}$ & - & $\mathrm{Y}$ & 3 & 7 \\
\hline 28 & M & 40 & II & - & - & $\mathrm{Y}$ & 2 & 5 \\
\hline 29 & $\mathrm{~F}$ & 55 & II & - & - & $\mathrm{Y}$ & 2 & 5 \\
\hline 30 & M & 51 & IV & $\mathrm{L}$ & Bil & $\mathrm{N}$ & 8 & 10 \\
\hline
\end{tabular}

$\mathrm{L}=$ left sided lesion; $\mathrm{R}=$ right sided lesion; $\mathrm{Bil}=$ bilateral lesion; $-=$ no detectable lesion; $\mathrm{Y}=$ rectus gyrus resection; $\mathrm{N}=$ no rectus gyrus resection; $\mathrm{SAH}=$ subarachnoid haemorrhage.

World Health Organisation, were taken into consideration. ${ }^{1617}$

\section{Patients and methods}

Thirty patients after rupture and repair of ACoA aneurysm were included in the study. On admission, standard neuropsychological testing disclosed neurobehavioural deficits of different quality and degree. Therapy was stopped when neurobehavioural dysfunction showed no further improvement. Comprehensive neuropsychological testing took place shortly before discharge.

The mean age of the patients ( 18 women and 12 men) was 54.3 (range: 37 to 72 )years. The severity of subarachnoid haemorrhage was rated using the Hunt and Hess scale. ${ }^{18}$ Aneurysms were normally clipped via a right craniotomy. A left sided approach was used only when the aneurysmal neck and the feeding arteries were more easily accessible from the left. Resection of part of the rectus gyrus was performed in 17 patients with high positioned aneurysms. Postsurgery MRI showed whether patients had lesions in the so called septohippocampal system, especially in the medial septum/nucleus of the diagonal band of Broca (MS/ndbB) complex. The lesion extent of each patient was transferred to the appropriate reference section of the Talairach and Tournoux atlas corresponding to the area immediately anterior to the optic chiasma containing the septum pellucidum, septal nuclei, diagonal band nuclei, area subcallosa, diagonal band of Broca, nucleus accumbens, putamen, and head of the caudate nucleus. ${ }^{19}{ }^{20}$ One of the limitations in terms of anatomical assessment was that the clips produced artefacts so the lesions could only be established with a high degree of probability but not with absolute certainty.

The neuropsychological study was conducted in two phases. The appendices contain detailed information on the comprehensive test battery used to assess the neurobehavioural impairments at discharge two to 13 months after surgery (mean duration: 5.2 months). In addition, psychopathological symptoms such as confabulation, anosognosia, apathy, and affective disorder were rated on the basis of therapists' findings. The second part of the neuropsychological study was conducted between five and 38 months after surgery (mean duration 13.9 months). Patients and their relatives were contacted by phone. The functional independence measure (FIM) was used for rating the outcome in terms of activities of daily living and the Glasgow outcome scale (GOS) was used for rating the outcome with regard to occupational and psychosocial activities. ${ }^{48} 49$

Table 1 shows sample characteristics (sex, age at onset, grade of subarachnoid haemorrhage, lesion site, and resection of rectus gyrus, as well as time interval between brain lesions and cognitive testing and brain lesions and outcome rating).

DATA ANALYSES

The sample size $(n=30)$ was small relative to the number of test variables. Therefore, to avoid singularities and biases in the parameter estimations statistical analysis was performed with only five summary indices for the cognitive domains of orientation, memory, learning, attention, and executive functions and four summary indices for the psychopathological symptoms. Both these indices were defined as 
follows: Firstly, each single test result was rated as: (0) normal, (1) mildly impaired (scores are below the 25 th percentile), (2) moderately impaired (scores are below the 10th percentile), and (3) severely impaired (scores are below the 5 th percentile or the test could not be performed because of too serious impairment). Secondly, within each cognitive domain the mean of these rating scores over all corresponding tests was computed as the summary index. Data were subsequently transformed into z-scores to approach normal distribution and homogeneity in the data sample.

Agglomerative hierarchical cluster analysis was performed to identify patient groups with specific patterns of cognitive and psychopathological disorders. The squared Euclidean distance and the method of average linkage between groups were used to decide which cases or clusters should be combined at each step. $^{5051}$

Multiple regression analysis was performed to determine whether a linear association exists between rehabilitation outcome and the aforementioned summary indices and, if so, to what extent cognitive, psychological, and neuroanatomical pathology might influence the rehabilitation outcome as measured by the GOS. The association between the ordinal scaled vari-

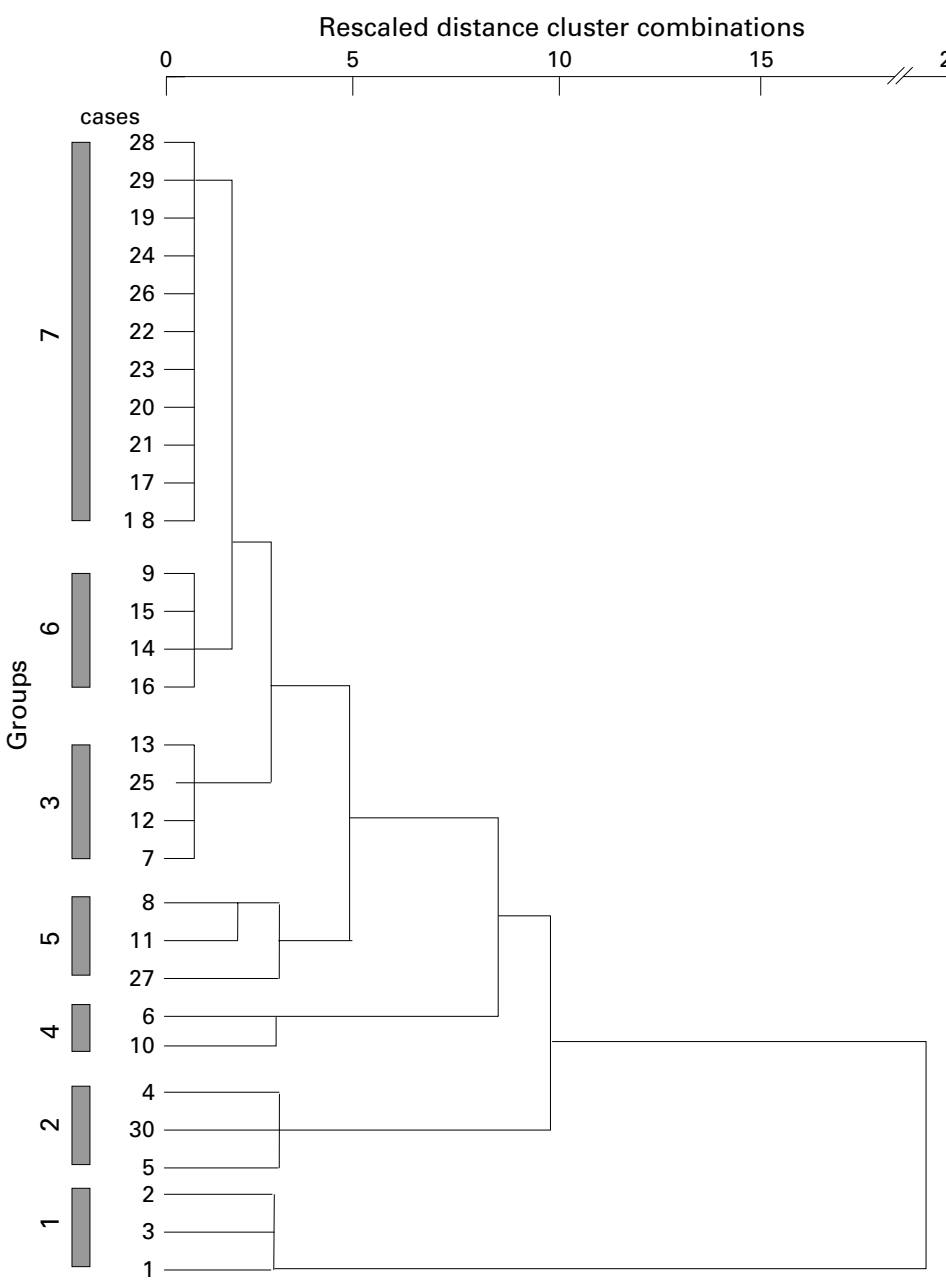

Figure 1 Dendrogram of cluster analysis using average linkage between groups. Vertical lines denote joined clusters whereas their corresponding positions on the distance scale at the top indicate the distances at which clusters were joined. ables of the FIM and GOS scales was tested for significance with the Spearman rank correlation coefficient.

Contingency tables with Pearson $\chi^{2}$ and Somers' d statistics were used to analyse the association between neuropsychological and psychopathological disturbances on the one hand and neuropathological findings expressed as categorical data on the other (for Pearson $\chi^{2}$ statistics $\mathrm{MS} / \mathrm{ndbB}$ and prefrontal lesions: $0=$ no lesion, $1=$ left-sided, $2=$ right-sided and $3=$ bilateral lesion; rectus gyrus: $0=$ no resection, $1=$ resection; Hunt and Hess: graded from 1 to 5; for Somers' d statistics MS/ndbB and prefrontal lesions were recoded into three classes: $0=$ no lesion, $1 / 2=$ lesion on one side only, $3=$ bilateral lesion). The Somers' d statistic is a measure of association for a contingency table of ordinal variables. ${ }^{52}{ }^{53}$ It is appropriate for the asymmetric case in which one variable is considered to be dependent and the other the predictor or explanatory variable. For tables larger than $3 \times 3$ and/or with low $(n<5)$ absolute frequencies in the cells, the $\mathrm{p}$ values of the $\chi^{2}$ statistics were calculated by Monte Carlo simulations. Exact $\mathrm{p}$ values are in such cases difficult to compute, whereas the asymptotic $p$ values carry no probabilistic guarantee whatsoever as to their accuracy. Monte Carlo simulations are available within the heading "exact tests" of SPSS/PC for WINDOWS.

For inferential statistics an $\alpha=0.05$ was accepted as a nominal level of significance. To keep the type I error $<0.05$ all tests were performed at a reduced level of significance (adjusted $\alpha$ according to the Bonferroni procedure).

\section{Results}

The degree of impairment in memory, learning, attention, and executive functions ranged from severe, moderate, or slight dysfunctions in some patients with ACoA to nearly normal ability in others. The detailed frequency distributions for each test are presented in the appendices.

Appendices 1 and 2 show that the following areas were particularly poor within the domain of memory and learning: the processes of encoding information (that is, working memory for complex material (appendix 1, test $5)$ ), short term recall of non-verbal material without convenient context (appendix 1, test 9) as well as learning sets of discrete verbal information (appendix 2, tests 3 and 4). Memory spans (appendix 1, tests 2 and 3) and remote and implicit memory (appendix 1, tests 11, 12, and 13) were normal in most patients.

Appendix 3 indicates that only few patients showed no impairment in each test examining attentional processes. If there were deficits in selective attention (appendix 3, tests 2 and 3), they occurred in most cases in the form of increased interference. Information processing speed in the case of complex requirements (appendix 3, test 1), divided attention (appendix 3 , tests 5 and 6 ) as well as sustained attention (appendix 3, test 8) were often reduced.

Appendix 3 also shows, that within the domain of executive functions, about half of 
Table 2 Patterns of cognitive and psychopathological dysfunctions at discharge; functional, occupational, and psychosocial outcome at least five months after injury

\begin{tabular}{|c|c|c|c|c|c|c|c|c|c|c|c|}
\hline Case No & Orientation & Attention & Memory & Learning & Planning & Confabulation & Anosognosia & Apathy & Affect & FIM & GOS \\
\hline \multicolumn{12}{|l|}{ Group 7: } \\
\hline 28 & - & $\star$ & - & - & - & - & - & - & - & 126 & 5 \\
\hline 29 & - & $\star$ & $\star$ & - & - & - & - & - & - & 124 & 4 \\
\hline 19 & - & $\star$ & - & - & - & - & - & - & - & 125 & 5 \\
\hline 24 & - & - & - & - & - & - & - & - & - & 126 & 5 \\
\hline 26 & - & $\star$ & _ & _- & _- & _ & _- & _- & _- & 126 & 5 \\
\hline 22 & - & $\star$ & - & - & - & - & - & - & - & 125 & 5 \\
\hline 23 & - & - & - & - & - & - & - & - & - & 124 & 5 \\
\hline 20 & - & * & - & - & - & - & - & - & - & 125 & 5 \\
\hline 21 & - & - & - & - & - & - & - & - & - & 126 & 5 \\
\hline 17 & - & $\star$ & - & - & $\star$ & - & - & - & - & 125 & 4 \\
\hline 18 & - & $\star$ & - & - & $\star$ & - & - & - & - & 125 & 4 \\
\hline \multicolumn{12}{|l|}{ Group 6: } \\
\hline 9 & - & $\star \star$ & - & $\star$ & $\star$ & - & - & - & - & 124 & 4 \\
\hline 15 & - & $\star \star$ & - & $\star$ & - & - & - & - & - & 125 & 4 \\
\hline 14 & - & $\star \star$ & - & $\star$ & - & - & - & - & - & 125 & 4 \\
\hline 16 & - & $\star \star$ & - & - & $\star$ & - & - & - & - & 125 & 4 \\
\hline \multicolumn{12}{|l|}{ Group 3: } \\
\hline 13 & - & $\star$ & $\star$ & $\star \star$ & - & - & - & - & - & 123 & 4 \\
\hline 25 & - & $\star$ & $\star$ & $\star \star$ & - & - & - & - & - & 124 & 4 \\
\hline 12 & - & * & $\star \star$ & $\star \star$ & $\star$ & - & - & - & - & 118 & 4 \\
\hline 7 & - & $\star$ & $\star \star$ & $\star \star$ & $\star$ & - & - & - & - & 116 & 4 \\
\hline \multicolumn{12}{|l|}{ Group 5: } \\
\hline 8 & - & $\star \star$ & - & $\star \star$ & $\star \star \star$ & - & - & * & $\star$ & 124 & 4 \\
\hline 11 & - & $\star$ & - & $\star$ & $\star$ & - & - & $\star$ & $\star$ & 124 & 5 \\
\hline \multirow{2}{*}{\multicolumn{12}{|c|}{ Group 4: }} \\
\hline & & & & & & & & & & & \\
\hline 6 & - & $\star \star \star \star$ & * & $\star \star$ & $\star \star \star \star$ & - & - & $\star \star \star$ & - & 103 & 4 \\
\hline 10 & - & $\star \star$ & $\star$ & $\star$ & $\star \star$ & - & - & $\star \star$ & - & 123 & 4 \\
\hline \multicolumn{12}{|l|}{ Group 2: } \\
\hline 4 & $\star \star$ & $\star \star \star$ & $\star \star \star \star$ & 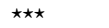 & $\star \star$ & - & - & - & $\star \star$ & 114 & 3 \\
\hline 30 & $\star$ & $\star \star$ & $\star \star$ & $\star \star$ & $\star \star$ & $\star$ & - & $\star$ & $\star$ & 104 & 3 \\
\hline 5 & $\star$ & $\star \star$ & $\star \star$ & $\star \star$ & $\star \star$ & - & - & - & $\star \star$ & 119 & 3 \\
\hline \multicolumn{12}{|l|}{ Group 1: } \\
\hline 3 & $\star \star \star$ & $\star \star$ & $\star \star \star$ & $\star \star \star$ & $\star \star \star$ & $\star \star \star$ & $\star \star$ & - & 夫 & 114 & 3 \\
\hline 2 & 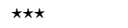 & $\star \star \star \star$ & $\star \star \star \star$ & 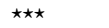 & 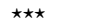 & $\star \star \star \star$ & 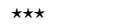 & - & - & 103 & 3 \\
\hline 1 & $\star \star \star$ & $\star \star \star$ & $\star \star \star$ & $\star \star \star$ & $\star \star \star$ & $\star \star \star$ & $\star \star \star$ & $\star \star \star$ & - & 32 & 3 \\
\hline
\end{tabular}

$\star \star \star \star$ severe impairment; ${ }^{\star \star}$ moderate impairment; ${ }^{\star}$ slight impairment; -=no impairment; FIM=functional independence measure; GOS $=$ Glasgow outcome scale.

the patients had a reduction of cognitive flexibility (appendix 3, test 10). In addition, they showed an inadequate overview of relevant conditions, a loss of concept formation, and a need for more time to finish the planning task and the Tower of Hanoi puzzle (appendix 3 , tests 11 and 12), as a result of attentional and working memory dysfunctions. Verbal fluency (appendix 3, test 13) was diminished in many patients, whereas intelligence (appendix 3, tests 14 and 15) was spared in most.

Figure 1 shows the dendrogram of a cluster analysis of all 30 patients using the five summary indices for orientation, memory, learning, attention, and executive functions as well as the four rating indices for the psychopathological symptoms (confabulation, anosognosia, apathy, and affective disorder). If point 4 on the distance scale of the dendrogram is used as a cut off point then five groups with specific patterns of cognitive and psychopathological dysfunctions can be differentiated. One of these can further be divided into three subgroups with specific patterns, so that altogether seven groups with characteristic patterns can be established.

Table 2 provides a summary of these seven patterns. Groups 1, 2, and 3 form a main pattern of primary memory impairment. In the first group, patients 1-3 were disoriented in nearly all modalities. Furthermore, they could not remember or learn anything. Therefore, attentional and problem solving processes could not be investigated by tests. All these patients showed a striking tendency towards confabulation and were characterised by severe anosognosia. Patients 4, 5, and 30 in the second group differed from the first group in so far as their orientation deficits were ascribed to memory disturbances and because they were able to learn and to remember several new items of information. These patients were aware of their cognitive dysfunctions and had affective disorders such as depression, anxiety, and low self confidence. Patients in the third group $(7,12,13,25)$ were fully oriented in all modalities. They were characterised by slight to moderate memory and learning dysfunctions. As a consequence of these disturbances, problem solving and attentional processes were reduced slightly. In these patients no psychopathological symptoms were found.

Groups 4 and 5 form a main pattern of primary impairment of executive and attentional functions. The patients in the fourth group (6, 10) were characterised by moderate to severe apathy, moderate to severe attentional and problem solving impairment, and only slight impairment in memory. The patients in the fifth group $(8,11,27)$ showed similar disturbances, but to a lesser degree.

Groups 6 and 7 form a main pattern of primary attention impairment. In the sixth group (patients 9, 14-16) the main symptom was a moderate attentional dysfunction. As a result of this disturbance learning or problem solving processes were reduced to a slight degree. In the seventh group the main symptom was a slight attentional deficit (patients 17-20, 22, $26,28,29)$, mostly without dysfunctions in other cognitive domains. 


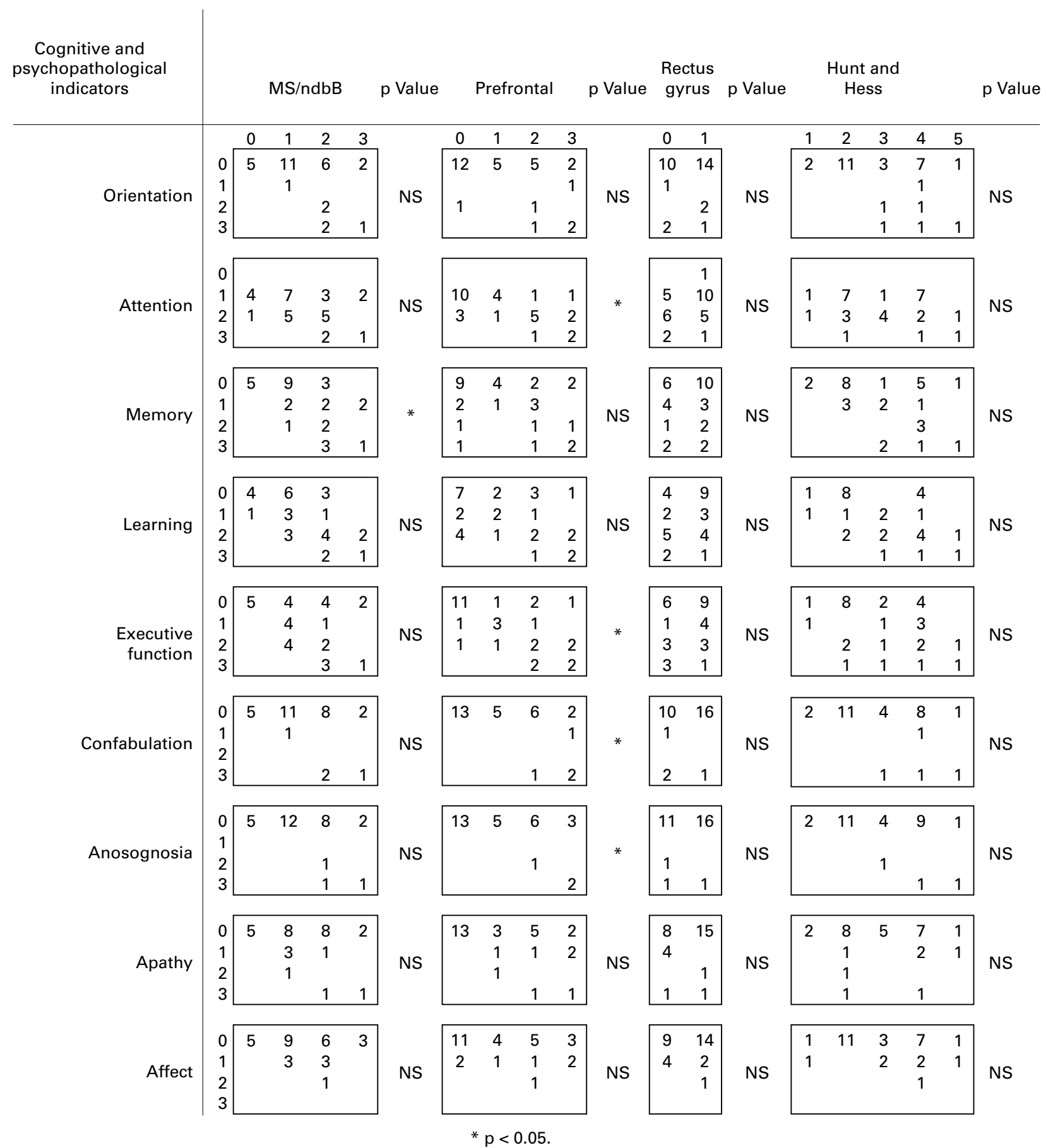

Figure 2 Frequency distributions of the cognitive and psychopathological indices within the various categories of the variables MS/ndbB and prefrontal lesions, rectus gyrus resection, and Hunt and Hess grading system. The results of the corresponding tests of independence performed with the Pearson $\chi^{2}$

Table 2 also displays the scores obtained by each patient using the FIM and the GOS. Spearman rank correlation between the GOS and FIM scores was highly significant $(r=0.80$; $\mathrm{p}<0.05)$. The GOS demonstrated "severe handicap" (score 3) for patients with severe and moderate memory disorders, "moderate handicap" (score 4) for patients with slight memory disorders, with executive dysfunctions and with moderate attentional disturbances, and "good recovery" for patients with only slight attentional disturbances.

Based on the transformed data a multiple regression analysis showed that memory ( $\beta$ coefficient $=-0.508, \mathrm{p}<0.05)$ and attentional processes $(\beta$ coefficient $=-0.459, p<0.05)$ were good predictors for outcome as measured by the GOS, whereas executive dysfunctions, psychopathology, and neuropathology were not able to predict the outcome. The amount of variance explained by the regression model was about $75 \%$.

Figure 2 presents a summary of associations between neuroanatomical and neurobehavioural variables. There was no significant association between the Hunt and Hess grading 


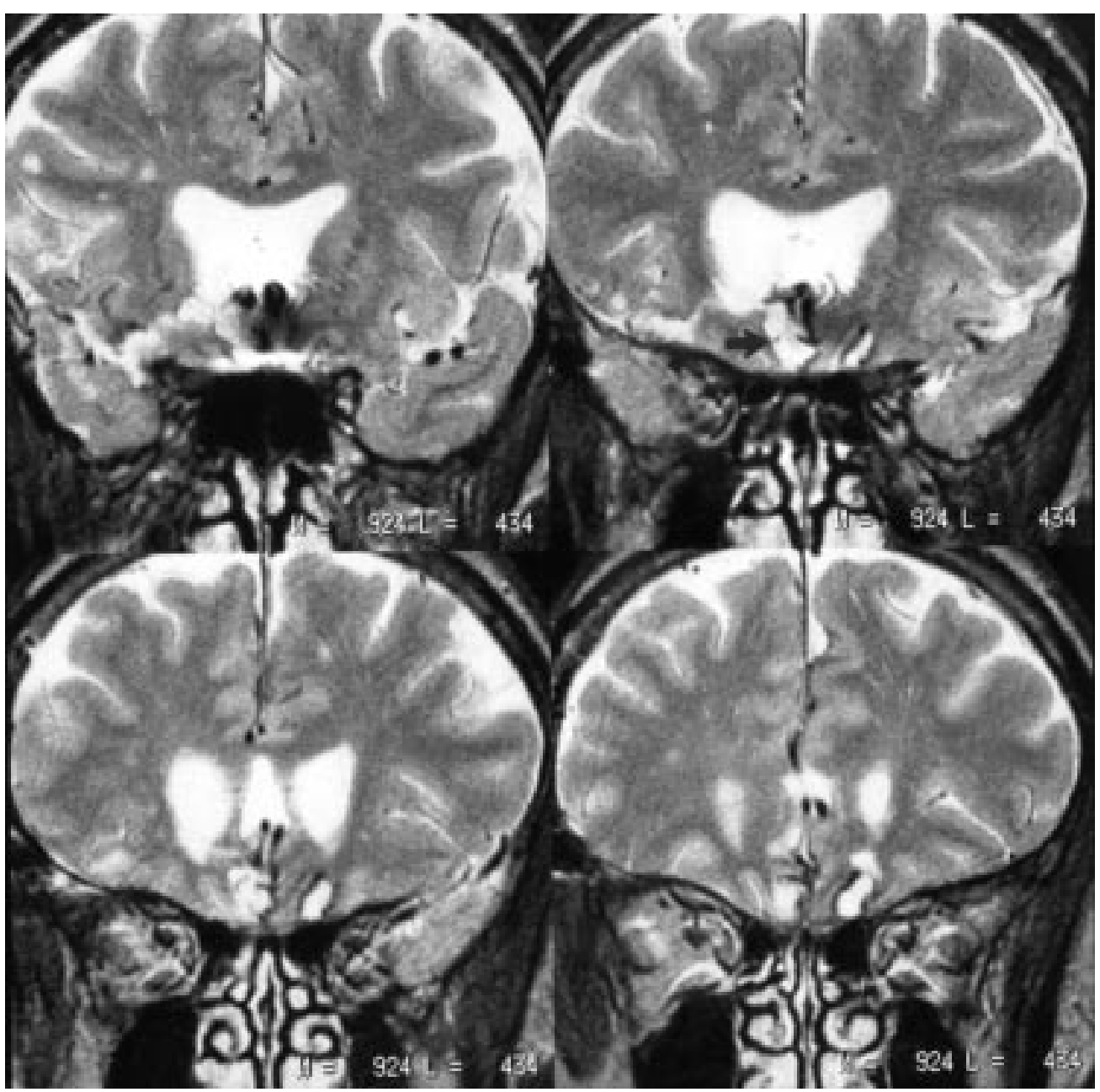

Figure 3 T2 weighted MRI of patient 4: coronal sections show (especially in the top right-black arrow -and bottom left) involvement of the right sided MS/ndbB complex as well as bilateral lesions of the rectus gyrus together with the clip artefact.

system or the resection of the rectus gyrus and any of the neurobehavioural variables. There was a significant association between the occurrence of lesions of the $\mathrm{MS} / \mathrm{ndbB}$ complex and memory deficits (Pearson $\chi^{2}$ statistic 16.74; $\mathrm{p}<0.05)$ in so far as in the case of bilateral lesions these deficits were more profound than in the case of unilateral ones (Somers' $\mathrm{d}=0.503$; $\mathrm{p}<0.05)$. On the other hand, lesion side had no significant effect on the severity of these dysfunctions. There was also a significant association between the occurrence of prefrontal lesions and deficits of attention, executive dysfunctions, confabulations, and anosognosia (corresponding values of the Pearson $\chi^{2}$ statistics 14.85, 21.20, 13.05, 13.05; p values<0.05). Bilateral lesions led to more severe deficits than unilateral ones (corresponding Somers' d values for attention, executive functions, confabulations, and anosognosia $0.491,0.548,0.571$, $0.476 ; \mathrm{p}$ values $<0.05)$. Again, lesion side had no significant effect on the severity of these dysfunctions. Apathy seemed to be only marginally influenced by prefrontal lesions and rectus gyrus resection, because the $\mathrm{p}$ values of the corresponding Pearson $\chi^{2}$ statistics were close to the level of significance $(0.074$ and 0.053 , respectively). Figure 3 shows brain MRI of patient 4 with a right sided lesion of the MS/ndbB complex.

\section{Discussion}

First of all it has to be emphasised that our patient sample is not generally representative of all patients after rupture and repair of ACoA aneurysms, as only those patients were included who were admitted to a rehabilitation unit because of neurobehavioural symptoms or complaints.

Our findings on the domain of memory and learning are consistent with those of other investigators. For storage processes long term memory is more impaired than short term memory. ${ }^{3615}$ For retrieval processes free recall is more affected than cued recall or recognition..$^{2-411}$ In the temporal dimension anterograde amnesia is much more pronounced than retrograde, memory spans are preserved, and, finally, implicit memory and procedural learning are undisturbed in most patients. ${ }^{25611}$ For deficits of source memory or sequencing which were reported to be typical for frontal lobe lesions we found such dysfunctions but they were not generally predominant. ${ }^{35} 54$

For encoding processes-that is, working memory and learning-current models for 
neuronal information processing seem to be of special interest. Working memory means simultaneous storage as well as processing, integration or manipulation of a set of single items of information for a short time and with limited capacity, whereas learning is the processing of more complex information by repetition and the use of strategies over a longer period and with large capacity. ${ }^{55}$ Prerequisites for these processes are control mechanisms and executive functions belonging to the "supervisory attentional system". ${ }^{57}$ The basis for such complex cognitive functions are neuronal networks consisting of small and large neuronal units interacting intensively with each other. ${ }^{58-60}$ Lesions of the $\mathrm{MS} / \mathrm{ndbB}$ complex in patients with ACoA affect an important interface between the hippocampus and the ascending reticular activating system. ${ }^{61}$ Therefore, it is not surprising that complex cognitive abilities such as working memory and learning are particularly often impaired in these patients.

For attentional functions, the findings of the present study point to the fact that slight impairment within this cognitive domain occurs often. If there are deficits in selective attention, they occur as increased interference in most cases. Deficient attentional inhibitory mechanisms were reported in another study also. ${ }^{10}$ Furthermore, the results of the present study very often showed a reduced information processing speed (especially in the case of complex requirements), poor divided attention ability, and a reduction of sustained attention and increased distractibility. Altogether only three of the 30 patients with ACoA had normal attentional functions in all investigated aspects.

Within the domain of executive functions, our findings of a reduced cognitive flexibility are consistent with those of others. ${ }^{8912}$ In addition, the ability to coordinate plans and to develop strategies for problem solving was impaired, manifest as a loss of concept formation, an inadequate grasp of essential items of information, and an increase in the time required to perform tasks. The secondary causes of such deficits were memory and attention dysfunctions. As a last separate test result verbal fluency deserves comment. In the present study as well as in many others verbal fluency often proved to be impaired..$^{561013} \mathrm{In}$ one study, reduced retrieval of verbal items from semantic memory was the only remaining deficit of patients with AcoA. ${ }^{62}$

Neuropsychological (dys)functions should not be considered in isolation, but in reciprocal interactions. This was made clear by the results of a cluster analysis. Seven specific patterns of cognitive and psychopathological dysfunctions could be differentiated. These impairment patterns fit in well with those differentiations described in previous studies, but they expand the wide range of cognitive dysfunctions especially for attentional impairment and the interrelation between disorders of individual cognitive components. ${ }^{72-14}$

For the outcome results it has to be emphasised that, besides memory, attention processes were especially good predictors. That mainly working memory was affected indicates that attentional disturbances are associated to a high degree with this brain function.

The pivotal role of the MS/ndbB complex in memory/learning processes was shown for the first time in humans by the well known postmortem study of Phillips et al..$^{5}$ Our findings of a significant association between the occurrence of lesions of the MS/ndbB complex and memory deficits confirm the fact that this basal forebrain region is an important interface within the so called septohippocampal system. Lesion side did not influence the severity of neuropsychological dysfunctions even in relation to memory deficits as opposed to diencephalic or mediotemporal amnesia, in which left sided affections produce more severe dysfunctions..$^{59}$ Perhaps this lack of lateralisation in the case of basal forebrain lesions might be explained by the fact that the main output fibres project via the fornix to the ipsilateral and via the fornix commissure to the contralateral hippocampus also. Nevertheless, bilateral forebrain lesions do produce more severe memory deficits than unilateral ones. The correlation between prefrontal lesions and deficits of attention, executive dysfunctions, and psychopathological disturbances was expected because of the well known role of this heteromodal association cortex in respect of these brain functions. ${ }^{63} \mathrm{We}$ could not confirm the results of the study of Irle et al who reported that only combined lesions of the basal forebrain (or basal forebrain and ventral frontal cortex) and striatum were associated with severe memory deficits. ${ }^{7}$ In our patients striatal lesions played no part in this respect. Our finding that resection of the rectus gyrus did not influence outcome is in accordance with a recent study. ${ }^{64}$

The question whether or not hydrocephalus or vasospasm had any impact on the patients studied can be answered as follows. In four cases with hydrocephalus this complication was immediately recognised and cured by shunt implantation. Therefore, hydrocephalus can be excluded as a long lasting cause of neurobehavioural deficits in our patient sample. The issue of vasospasm was not considered in this study, as we were only interested in the lesion site responsible for certain deficits irrespective of the cause of the lesions. It may well be possible that, for example, some of the MS/ NdbB complex lesions were caused by vasospasm. It is almost impossible to differentiate whether such lesions result from vasospasm or tearing during the neurosurgical procedure.

In summary, based on our neurobehavioural and neuropathological findings, the legitimacy of the concept of an "ACoA syndrome" has to be denied. There are various patterns of neuropsychological impairment. This has implications for rehabilitation, in so far as the planning and selecting of specific therapeutic techniques need to be carried out according to the underlying patterns of cognitive disturbance and the psychosocial background. In this context, it must be emphasised that patients with only minor deficits, but complex occupational or social demands require individually adapted-tailor made-rehabilitative approaches. 


\section{Appendices}

Appendix 1: Results of cognitive testing: orientation and memory ( $n=30$ ACoA patients)

\begin{tabular}{|c|c|c|c|c|}
\hline Cognitive test/scale & $\begin{array}{l}\text { Patients } \\
n \geqslant 25 \% \text { ile/ } \\
\text { without } \\
\text { impairment } \\
\text { (n) }\end{array}$ & $\begin{array}{l}\text { Patients } \\
25 \% \text { ile }>n \geqslant \\
10 \% \text { ile/ slight } \\
\text { impairment } \\
\text { (n) }\end{array}$ & $\begin{array}{l}\text { Patients } \\
10 \% \text { ile }>n \geqslant \\
5 \% \text { ile/ moderate } \\
\text { impairment } \\
\text { (n) }\end{array}$ & $\begin{array}{l}\text { Patients } \\
n<5 \% \text { ile/ } \\
\text { severe } \\
\text { impairment } \\
(n)\end{array}$ \\
\hline \multicolumn{5}{|l|}{ Orientation: } \\
\hline Questionnaire ${ }^{21}$ & 24 & 2 & 1 & 3 \\
\hline \multicolumn{5}{|l|}{ Memory span/working memory: } \\
\hline \multicolumn{5}{|l|}{ Digit $\operatorname{span}^{22}$ : } \\
\hline Forward & 26 & 2 & 1 & 1 \\
\hline Backward & 22 & 4 & 2 & 2 \\
\hline \multicolumn{5}{|l|}{ Corsi block tapping test ${ }^{26}$ : } \\
\hline Forward & 25 & 3 & 1 & 1 \\
\hline Backward & 21 & 4 & 2 & 3 \\
\hline Word list ${ }^{23}$ & 22 & 3 & 2 & 3 \\
\hline Reading $\operatorname{span}^{2425}$ & 16 & 6 & 4 & 4 \\
\hline \multicolumn{5}{|l|}{ Short and long term memory: } \\
\hline \multicolumn{5}{|l|}{ Short story ${ }^{27}$ : } \\
\hline Immediate recall & 20 & 4 & 3 & 3 \\
\hline Recall after 48 hours & 18 & 5 & 3 & 4 \\
\hline \multicolumn{5}{|l|}{ Long story ${ }^{23}$ : } \\
\hline Immediate recall & 19 & 4 & 3 & 4 \\
\hline Recall after 48 hours & 17 & 6 & 3 & 4 \\
\hline Recognition memory test/faces ${ }^{28}$ & 19 & 5 & 3 & 3 \\
\hline \multicolumn{5}{|l|}{ Complex figure test ${ }^{29}$ : } \\
\hline Copy & 21 & 4 & 2 & 3 \\
\hline Immediate free recall & 16 & 5 & 5 & 4 \\
\hline \multicolumn{5}{|l|}{ Prospective memory: } \\
\hline Agreements $^{23}$ & 17 & 5 & 4 & 4 \\
\hline \multicolumn{5}{|l|}{ Remote memory: } \\
\hline Autobiographical memory ${ }^{23}$ & 26 & 2 & 1 & 1 \\
\hline \multicolumn{5}{|l|}{ Famous faces (modified) ${ }^{23}$ : } \\
\hline Free recall & 24 & 2 & 1 & 3 \\
\hline Cued recall & 26 & 1 & 0 & 3 \\
\hline \multicolumn{5}{|l|}{ Implicit memory: } \\
\hline Incomplete pictures test ${ }^{30}$ & 24 & 2 & 1 & 3 \\
\hline
\end{tabular}

$\mathrm{ACoA}=$ Anterior communicating artery aneurysm.

Appendix 2: Results of cognitive testing: learning (n=30 ACoA patients)

\begin{tabular}{|c|c|c|c|c|}
\hline Cognitive test/scale & $\begin{array}{l}\text { Patients } \\
n \geqslant 25 \% \text { ile/ } \\
\text { without } \\
\text { impairment } \\
\text { (n) }\end{array}$ & $\begin{array}{l}\text { Patients } \\
25 \% \text { ile }>n \geqslant \\
10 \% \text { ile/ slight } \\
\text { impairment } \\
\text { (n) }\end{array}$ & $\begin{array}{l}\text { Patients } \\
10 \% \text { ile }>n \geqslant \\
5 \% \text { ile/ } \\
\text { moderate } \\
\text { impairment } \\
\text { (n) }\end{array}$ & $\begin{array}{l}\text { Patients } \\
n<5 \% \text { ilel } \\
\text { severe } \\
\text { impairment } \\
\text { (n) }\end{array}$ \\
\hline \multicolumn{5}{|l|}{ Associates: } \\
\hline Learning of word paired associates ${ }^{23}$ & 16 & 5 & 6 & 3 \\
\hline Learning of face-name paired associates ${ }^{23}$ & 15 & 3 & 8 & 4 \\
\hline \multicolumn{5}{|l|}{ Separated informations: } \\
\hline \multicolumn{5}{|l|}{ Selective reminding test ${ }^{31}$ : } \\
\hline Long term storage & 13 & 3 & 6 & 8 \\
\hline Consistent long term recall & 12 & 3 & 5 & 10 \\
\hline \multicolumn{5}{|l|}{ California verbal learning test (German version) $)^{32}$ : } \\
\hline Trial 5 & 14 & 2 & 8 & 6 \\
\hline Short delay/free recall & 13 & 5 & 6 & 6 \\
\hline Short delay/cued recall & 17 & 4 & 4 & 5 \\
\hline Long delay/free recall & 15 & 5 & 4 & 6 \\
\hline Long delay/cued recall & 17 & 2 & 5 & 6 \\
\hline Long delay/recognition & 18 & 3 & 4 & 5 \\
\hline Recurring figures test ${ }^{33}$ & 14 & 4 & 7 & 5 \\
\hline \multicolumn{5}{|l|}{ Spatial positions: } \\
\hline \multicolumn{5}{|l|}{$7 / 24$ Spatial recall test ${ }^{31}$ : } \\
\hline Recall (trial 1 to 5) & 14 & 4 & 8 & 4 \\
\hline Recall after interference & 15 & 5 & 6 & 4 \\
\hline Delayed recall after 20 minutes & 16 & 4 & 6 & 4 \\
\hline \multicolumn{5}{|c|}{ Contextual information: } \\
\hline \multicolumn{5}{|c|}{ Recall, recognition, and spatial localisation of objects (modified) $)^{34}$ : } \\
\hline Recall of objects (trial 1 to 4 ) & 16 & 4 & 6 & 4 \\
\hline Recognition of objects (trial 1 to 4 ) & 18 & 5 & 3 & 4 \\
\hline Localisation of objects (trial 1 to 4 ) & 16 & 3 & 7 & 4 \\
\hline Delayed recall of objects (after 24 hours) & 15 & 6 & 5 & 4 \\
\hline Delayed recognition of objects (after 24 hours) & 18 & 4 & 4 & 4 \\
\hline Delayed localisation of objects (after 24 hours) & 15 & 7 & 4 & 4 \\
\hline \multicolumn{5}{|l|}{ Recognition and temporal order of faces (modified) ${ }^{35}$ : } \\
\hline Recognition of faces (trial 1 to 4 ) & 21 & 2 & 3 & 4 \\
\hline Order of faces (trial 1 to 4 ) & 15 & 4 & 7 & 4 \\
\hline Delayed recognition of faces (after 24 hours) & 20 & 3 & 3 & 4 \\
\hline Delayed order of faces (after 24 hours) & 14 & 5 & 7 & 4 \\
\hline
\end{tabular}

$\mathrm{ACoA}=$ Anterior communicating artery aneurysm. 
Appendix 3: Results of cognitive testing: attention and executive functions ( $n=30$ ACoA patients)

\begin{tabular}{|c|c|c|c|c|}
\hline Cognitive test/scale & $\begin{array}{l}\text { Patients } \\
n \geqslant 25 \% \text { ile/ } \\
\text { without } \\
\text { impairment } \\
(n)\end{array}$ & $\begin{array}{l}\text { Patients } \\
25 \% \text { ile }>n \geqslant \\
10 \% \text { ile/ slight } \\
\text { impairment } \\
\text { (n) }\end{array}$ & $\begin{array}{l}\text { Patients } \\
10 \% \text { ile }>n \geqslant \\
5 \% \text { ile/ moderate } \\
\text { impairment } \\
\text { (n) }\end{array}$ & $\begin{array}{l}\text { Patients } \\
n<5 \% \text { ilel } \\
\text { severe } \\
\text { impairment } \\
\text { (n) }\end{array}$ \\
\hline \multicolumn{5}{|l|}{ Attention: } \\
\hline Trail making test/part $\mathrm{A}^{263637}$ & 14 & 6 & 4 & 6 \\
\hline \multicolumn{5}{|l|}{ Go-/No-Go test ${ }^{38}:$} \\
\hline Reaction time & 19 & 6 & 2 & 3 \\
\hline Error rate & 20 & 5 & 2 & 3 \\
\hline \multicolumn{5}{|l|}{ Stroop test (German version) $)^{39}{ }^{40}$ : } \\
\hline Reaction time & 16 & 7 & 4 & 3 \\
\hline Error rate & 18 & 7 & 2 & 3 \\
\hline \multicolumn{5}{|l|}{ Trail making test/part $\mathrm{B}^{26}$ : } \\
\hline Reaction time & 12 & 6 & 4 & 8 \\
\hline Error rate & 14 & 6 & 3 & 7 \\
\hline \multicolumn{5}{|l|}{ Divided attention test ${ }^{38}$ : } \\
\hline Reaction time & 6 & 6 & 6 & 12 \\
\hline Error rate & 9 & 6 & 5 & 10 \\
\hline \multicolumn{5}{|l|}{ Paced auditory serial addition task ${ }^{31}$ : } \\
\hline Easy & 8 & 4 & 6 & 12 \\
\hline Hard & 3 & 5 & 7 & 15 \\
\hline \multicolumn{5}{|l|}{ Vigilance test ${ }^{38}$ : } \\
\hline Reaction time & 17 & 5 & 4 & 4 \\
\hline Error rate & 12 & 6 & 5 & 7 \\
\hline Sustained attention $^{41}$ & 6 & 10 & 8 & 6 \\
\hline Distractibility ${ }^{41}$ & 11 & 10 & 4 & 5 \\
\hline \multicolumn{5}{|l|}{ Executive functions: } \\
\hline \multicolumn{5}{|l|}{ Planning and problem solving: } \\
\hline Modified card sorting test ${ }^{42}$ & 14 & 8 & 4 & 4 \\
\hline Planning task ${ }^{43}$ & 14 & 7 & 5 & 4 \\
\hline Tower of Hanoi puzzle ${ }^{44}$ & 15 & 9 & 2 & 4 \\
\hline \multicolumn{5}{|l|}{ Verbal fluency: } \\
\hline Controlled oral word association test ${ }^{31}$ & 8 & 9 & 11 & 2 \\
\hline \multicolumn{5}{|l|}{ Intelligence: } \\
\hline WAIS-R (German version) ${ }^{45} 46$ & 25 & 1 & 1 & 3 \\
\hline Raven progressive matrices ${ }^{47}$ & 25 & 1 & 1 & 3 \\
\hline
\end{tabular}

$\mathrm{ACoA}=$ Anterior communicating artery aneurysm.

1 Hütter BO, Gilsbach JM. Cognitive deficits after rupture and early repair of anterior communicating artery aneurysms. Acta Neurochirur (Wien) 1992;116:6-13.

2 Talland GA, Sweet WH, Ballantine HT. Amnesic syndrome with anterior communicating artery aneurysm. If Nerv Ment Dis 1967;145:179-92.

3 Volpe BT, Hirst W. Amnesia following the rupture and repair of an anterior communicating artery aneurysm. $\mathcal{F}$ Neurol Neurosurg Psychiatry 1983;46:704-9.

4 Damasio AR, Graff-Radford NR, Eslinger PJ, et al. Amnesia following basal forebrain lesions. Arch Neurol 1985;42:26371.

5 Phillips S, Sangalang V, Sterns G. Basal forebrain infarction: a clinicopathologic correlation. Arch Neurol 1987;44:11348 .

6 Alexander MP, Freedman M. Amnesia after anterior communicating artery aneurysm rupture. Neurology 1984 ; 34:752-4.

7 Irle E, Wowra B, Kunert HJ, et al. Memory disturbances following anterior communicating artery rupture. Ann Neurol 1992:31:473-80.

8 Mayes AR, Meudell PR, MacDonald C. Disproportionate intentional spatial-memory impairments in amnesia. Neuropsychologia 1991;29:771-84.

9 Shoqeirat MA, Mayes AR. Disproportionate incidental spatial-memory and recall deficits in amnesia. Neuropsychologia 1991;29:749-69.

10 Van der Linden M, Bruyer R, Roland J, et al. Proactive interference in patients with amnesia resulting from anterior communicating artery aneursym. $\mathcal{F}$ Clin Exp Neuropsychol 1993;15:525-36.

11 Bondi MW. Implicit and explicit memory following anterior communicating artery aneurysm rupture. Brain $\operatorname{Cog} n$ 1993;22:213-29.

12 Stenhouse LM, Knight RG, Longmore BE, et al. Long-term cognitive deficits in patients after surgery on aneurysms of
the anterior communicating artery. $\mathcal{F}$ Neurol Neurosurg Psythe anterior communicating $1991 ; 54: 909-14$.

13 Van der Linden $M$, Bruyer R. Troubles de la mémoire et signes de dysfonctionnement frontal chez vingt-neuf patients opérés d'un anévrysme de l'artère communicante antérieure. Acta Neurologica Belg 1992;92:255-77.

14 DeLuca J. Predicting neurobehavioral patterns following anterior communicating artery aneurysm. Cortex 1993;29: 639-47.

15 DeLuca J. Cognitive dysfunction after aneurysm of the anterior communicating artery. F Clin Exp Neuropsychol 1992;14:924-34

16 World Health Organisation. The international classification of impairments, disabilities, and handicaps. Geneva: WHO, 1980.

17 Wade DT. Measurement in neurological rehabilitation. Oxford: Oxford University Press, 1992.

18 Hunt WE, Hess RM. Surgical risk as related to the time of intervention in the repair of intracranial aneurysms. $\mathcal{F} \mathrm{Neu}$ rosurg 1968;28:14-20.
19 Talairach J, Tournoux P. Co-planar stereotaxic atlas of the human brain. 3-dimensional proportional system: an approach to cerebral imaging. Stuttgart: Thieme, 1988.

20 Niewenhuys R, Voogd J, van Huijzen C. The human central nervous system. A synopsis and atlas. Berlin: Springer, 1988.

21 Von Cramon D, Säring W, Störungen der Orientierung beim hirnorganischen Psychosyndrom. In: Bente D, Coper $\mathrm{H}$, Kanowski S, eds. Hirnorganische Psychosyndrome im Alter. Berlin: Springer, 1982:38-50.

22 Wechsler D. WMS-R: Wechsler memory scale - revised (manual). San Antonio: The Psychological Corporation, 1987

23 Schuri U. Gedächtnis. In: Von Cramon DY, Mai N, Ziegler W, eds. Neuropsychologische Diagnostik. Weinheim: VCH, 1993:91-122.

24 Daneman M, Carpenter PA. Individual differences in working memory and reading. $\mathcal{F}$ Verb Learn Verb Behav 1980;19: $450-66$.

25 Ems M, Troppmann N, Schuri U. Reading span-deutsche version. München: EKN-Materialien für die Rehabilitation, 1991.

26 Lezak MD. Neuropsychological assessment. 2nd ed. New York: Oxford Universitiy Press, 1983.

27 Böcher W. Erfahrungen mit dem Wechslerschen Gedächtnistest (Wechsler memory scale) bei einer deutschen Versuchsgruppe von 200 normalen Vpn. Diagnostica 1963;9:56-68.

28 Warrington EK. Recognition memory test. Windsor: NFERNelson, 1984.

29 Spreen O, Strauss E. A compendium of neuropsychological tests. Administration, norms and commentary. New York: Oxford Universitiy Press, 1991.

30 Gollin ES. Developmental studies of visual recognition of incomplete objects. Percept Motor Skills 1960;11:289-98.

31 Rao SM, Leo GJ, Haughton VM, et al. Correlation of magnetic resonance imaging with neuropsychological testing in multiple sclerosis. Neurology 1989;39:161-6.

32 Ilmberger J. Deutsche version of the Californian verbal learning tests. Institut für Medizinische Psychologie der Universität München, 1988

33 Hartje W, Rixecker H. Der recurring-figures-test von Kimura. Normierung an einer deutschen Stichprobe. Nervenarzt 1978;49:354-6.

34 Smith ML, Milner B. The role of the right hippocampus in the recall of spatial location. Neuropsychologia 1981;19: 781-93.

35 Shimamura AP, Janowsky JS, Squire LR. Memory for the temporal order of events in patients with frontal lobe lesions and amnesic patients. Neuropsychologia 1990;28: 803-13.

36 Oswald W, Roth E. Der Zahlenverbindungstest. Göttingen: Hogrefe, 1978.

37 Oswald WD, Fleischmann UM. Das Nürnberger Altersinventar. 2nd ed. Göttingen: Hogrefe, 1986. 
38 Zimmermann P, Fimm B. Neuropsychologische Testbatterie zur Erfassung von Aufmerksamkeitsdefiziten. TAP. Psycholo-
gisches Institut der Universität Freiburg, 1993.

39 Stroop JR. Studies of interference in serial verbal reactions f Exp Psychol 1935;18:643-62.

40 Bäumler G. Farbe-Wort-Interferenztest nach f.R. Stroop. Göttingen: Hogrefe, 1985

41 Frieboes R-M, Jürgensmeyer S, von Cramon DY. Neuropsychologische Defizite hypoxämisch hirngeschädigter $\mathrm{Pa}-$ tienten. Nervenheilkunde 1994;13:362-5.

42 Nelson HE. A modified card-sorting test sensitive to frontal lobe defects. Cortex 1976;12:313-24.

43 Von Cramon DY. Planen und Handeln. In: Zihl J, von Cramon DY, eds. Neuropsychologische Rehabilitation. Grundlagen, Diagnostik, Behandlungsverfahren. Berlin: Springer, 1988:248-63.

44 Klix F, Rautenstrauch-Goede K. Struktur- und Komponentenanalyse von Problemlöseprozessen. Zeitschr Psychol

45 Wechsler D. WAIS-R manual. New York: Psychological Corporation, 1981.

46 Dahl G. Reduzierter Wechsler-Intelligenztest. WIP. Meisenheim/Glan: Hain, 1972

47 Raven JC. Standard progressive matrices, sets $A, B, C, D, E$. Oxford: Oxford Psychologists Press, 1976

48 Granger CV, Hamilton BB, Sherwin SF. Guide for the use of the uniform data set for medical rehabilitation. New York: Uniform Data System for Medical Rehabilitation Project Office, Buffalo General Hospital, 1986.

49 Jennett B, Bond M. Assessment of outcome after severe brain damage. A practical scale. Lancet 1975;i:480-4

50 Anderberg MR. Cluster analysis for applications. New York: Academic Press, 1973

51 Fahrmeir I, Hamerle A, eds. Multivariate statistische Verfahren. Berlin: Walter de Gruyter, 1984.

52 Everitt BS. Dictionary of statistics in the medical sciences. Cambridge: Cambridge University Press, 1995.
53 Somers RH. A new asymmetric measure of association for ordinal variables. American Sociological Review 1962;27: ordinal varia $799-811$.

54 Schacter DL. Memory, amnesia, and frontal lobe dysfunction. Psychobiology 1987;15:21-36.

55 Baddeley AD, Hitch GJ. Working memory. In: Bower G, ed. Recent advances in learning and motivation. New York: Academic Press, 1974:47-90.

56 Baddeley $\mathrm{AD}$. The development of the concept of working memory: implications and contributions of neuropsychology. In: Vallar G, Shallice T, eds. Neuropsychological impairments of short term memory. Cambridge: Cambridge Univerments of short term memory.

57 Shallice T. Specific impairments of planning. Philos Trans $R$ Soc Lond B Biol Sci 1982;298:199-209.

58 Mesulam M-M. Large-scale neurocognitive networks and distributed processing for attention, language, and memory. Ann Neurol 1990;28:597-613.

59 Paulesu E, Frith CD, Frackowiak RSJ. The neural correlates of the verbal component of working memory. Nature 1993; 362:342-5.

60 Steiger HJ, Ilmberger J. Keeping in mind the mind: mental functions, networks, and neurosurgery. Acta Neurochir (Wientions, networks, and

61 Von Cramon DY, Schuri, U. The septo-hippocampal pathways and their relevance to human memory: a case pathways and their relevance
report. Cortex 1992;28:411-22.

62 Richardson JTE. Cognitive performance following rupture and repair of intracranial aneurysm. Acta Neurol Scand 1991;83:110-22

63 Mesulam M-M. Frontal cortex and behavior. Ann Neurol 1986;19:320-5.

64 Horikoshi T, Nukui H, Mitsuka S, et al. Partial resection of the gyrus rectus in pterional approach to anterior communicating artery aneurysms. Neurol Med Chir (Tokyo) 1992; 32:136-9. 